\title{
SISTEM INFORMASI KULIAH KERJA DAKWAH UNIVERSITAS MUHAMMADIYAH GORONTALO
}

\author{
Mohamad Ilyas Abas \\ Sistem Informasi Fakultas Sains dan Teknologi Universitas Muhammadiyah Gorontalo \\ Email: ilyasabas@umgo.ac.id \\ Irawan Ibrahim \\ Sistem Informasi Fakultas Sains dan Teknologi Universitas Muhammadiyah Gorontalo \\ Email: irawanibrahim@umgo.ac.id \\ Muslim Panigoro \\ Sistem Informasi Fakultas Sains dan Teknologi Universitas Muhammadiyah Gorontalo \\ Email: muslimpanigoro@gmail.com
}

\begin{abstract}
ABSTRAK
Kuliah Kerja Dakwah (KKD) merupakan program pengabdian kepada masyarakat melalui Lembaga Penelitian dan Pengabdian pada Masyarakat (LPPM). Berbeda dengan kuliah kerja mahasiswa di Universitas non Muhammadiyah, program lebih kolaborasi antara pengabdian sesuai bidang ilmu dan ditambahkan dengan program dakwah yang dilakukan di lokasi tempat pelaksanaan KKD. Pendaftar KKD yaitu mahasiswa yang sudah memenuhi persyaratan tertentu. Pendaftar dilakukan dengan cara konvensional dengan melibatkan dokumen secara manual dan memakan waktu yang lama. Akses menjadi lebih rumit karena tidak tersedianya sistem. Sistem ini dibuat untuk mengatasi permasalahan tersebut. Dengan adanya Sistem Informasi Kuliah Kerja Dakwah (SIKKD) pelayanan menjadi lebih mudah dari segi mahasiswa, Dosen Pembimbing Lapangan (DPL) serta panitia penyelenggara KKD. Tujuan penelitian ini yaitu dengan membuat Sistem Informasi KKD berbasis web yang dapat memudahkan proses registrasi sampai penilaian dalam sebuah sistem. Metode penelitian yang digunakan yakni Research and Development (RND) guna menghasilkan suatu produk yang benar-benar disempurnakan. Hasil penelitian ini SIKKD dapat mempermudah proses pengelolaan program KKD dengan baik menggunakan web dibandingkan hanya secara konvesional seperti yang dilakukan selama ini.
\end{abstract}

Kata kunci: mahasiswa, SIKKD, pelayanan.

\begin{abstract}
Lecture Work Dakwah (KKD) is a program of dedication to the community through the Institute of Research and Community Service (LPPM). In contrast to the university students' work at a Muhammadiyah University, more collaboration programs between the dedication of the field of science and added to the da'wah program conducted at the location where the KKD execution. KKD applicants are students who have met certain requirements. Registrants are made in a conventional manner by involving documents manually and takes a long time. Access becomes more complicated because of the unavailability of the system. This system is designed to solve the problem. With the Information System Kuliah Kerja Dakwah (SIKKD) the service becomes easier in terms of students, Field Supervisors (DPL) and KKD organizing committee. The purpose of this research is to create a Web-based KKD Information System that can facilitate the process of registration until the assessment in a system. The research method used is Research and Development (RND) to produce a product that really refined. The results of this study SIKKD can facilitate the process of KKD program management by using the web rather than just conventionally as it has been done so far.
\end{abstract}

Keywords: SIKKD, student, service.

\section{PENDAHULUAN}

Sistem informasi pada zaman sekarang bukan merupakan hal yang baru dalam mendukung segala bentuk pekerjaan. Seperti halnya untuk proses administrasi kependudukan yang dilakukan oleh [1] untuk memudahkan proses administrasi kependudukan untuk instansi terkait. Bahkan pada kasus akademisi yakni administrasi pengolahan skripsi [2] guna memudahkan proses pendaftaran skripsi mahasiswa agar 
pengelolaan lebih mudah tanpa proses yang lama menggunakan berkas. Hal ini sejalan dengan perkembangan sistem lainnya yang mempermudah proses administrasi registrasi Kuliah Kerja Dakwah (KKD) yang ada di Universitas Muhammadiyah Gorontalo (UMGO).

UMGO di bawah Lembaga Penelitian dan Pengabdian Masyarakat (LPPM) merupakan salah satu Lembaga perguruan tinggi yang tidak luput dari persoalan yang ada diantaranya bagian akademik, dari penerimaan mahasiswa studi akhir yang akan melaksanakan Kuliah Kerja Dakwah (KKD). Dari persoalan yang ada diharapkan bisa memanfaatkan teknologi informasi yang ada sebagai solusi pemecahan masalah untuk menghasilkan informasi yang diharapkan dengan menggunakan sistem pengolahan data. Dengan adanya Sistem Informasi kuliah kerja dakwah diharapkan mampu mempermudah dan mempercepat proses pengolahan data dengan mengembangkan sistem yang sudah ada sebelumnya. Seperti yang pernah diteliti sebelumnya oleh [3] [4] dengan membuat sistem informasi kuliah kerja nyata (KKN) untuk mengelola kegiatan tersebut. Adapun beberapa pengembangan penelitian serupa berbasis geografis telah dibuat oleh [5] [6] dengan membuat beberapa pengembangan untuk mempermudah proses registrasi dan pemantauan pada kegiatan posdaya ataupun KKN.

Proses KKD di LPPM Universitas Muhammadiyah Gorontalo selama ini sistem yang digunakan masih bersifat manual yaitu para calon mahasiswa KKD melakukan proses registrasi dengan memasukan data serta mengisi pada formulir pendaftaran, hal ini dapat menyebabkan staff dari LP2M UMGO sulit untuk membaca data mahasiswa dan prosesnya terlalu panjang. SIKKD yang dibuat dengan interface yang baik sehingga terkesan lebih user friendly. Validasi program lebih baik dengan adanya tingkatan user yang terdiri dari mahasiswa, fakultas, dan LPPM. Hal ini membuat sistem menjadi lebih baik dari segi tampilan dan penggunaannya.

\section{KAJIAN LITERATUR}

a) Sistem Informasi

Sistem Informasi merupakan suatu studi tentang pengembangan perangkat lunak untuk mengumpulkan, memproses, membuat maupun mendistribusikan data [7]. Seluruh komponen dalam sistem informasi saling berkaitan dan bekerjasama dalam proses pengambilan keputusan.

b) Komponen Sistem Informasi

Komponen sistem informasi dapat dijabarkan sebagai seluruh aspek/ variabel yang adap dalam sistem [7]:

1) Perangkat keras (Hardware)

Bagian dari sistem yang dapat disentuh (komponen fisik) teknologi. komputer, keyboard, disk drive, flash drive

2) Perangkat lunak (Software)

Perangkat instruksi yang memberitahu hardware apa yang harus dilakukan. Perangkat lunak dikenal sebagai perangkat yang tidak berwujud (tidak bisa disentuh). Saat programmer membuat program perangkat lunak, yang dilakukan hanyalah mengetik daftar instruksi yang memberitahu perangkat keras apa yang harus dilakukan. Ada beberapa kategori perangkat lunak, dengan dua kategori utama adalah perangkat lunak sistem operasi, yang membuat perangkat keras dapat digunakan, dan perangkat lunak aplikasi, yang melakukan sesuatu yang berguna. Contoh sistem operasi meliputi Microsoft Windows di komputer pribadi dan Google Android pada ponsel.

3) Data

Komponen ketiga adalah data. Data adalah kumpulan fakta. misalnya, alamat jalan, kota, tempat tinggal, dan nomor telepon adalah semua data. Seperti perangkat lunak, data juga tidak berwujud. Dengan sendirinya, potongan data tidak terlalu berguna. Tapi dikumpulkan, diindeks, dan diorganisasikan bersama ke dalam database.

4) Orang

Ketika memikirkan sistem informasi, mudah untuk berfokus pada komponen teknologi dan lupa bahwa kita harus melihat melampaui alat ini untuk sepenuhnya memahami bagaimana mereka berintegrasi ke dalam sebuah organisasi. Fokus pada orang-orang yang terlibat dalam sistem informasi adalah langkah selanjutnya. Dari pekerja help-desk front-line, analis sistem, hingga pemrogram, sampai ke chief information officer (CIO), orang-orang yang terlibat dengan sistem informasi merupakan elemen penting yang tidak boleh diabaikan.

5) Proses

Komponen terakhir dari sistem informasi adalah proses. Suatu proses adalah serangkaian langkah yang dilakukan untuk mencapai hasil atau tujuan yang diinginkan. Sistem informasi semakin terintegrasi dengan proses organisasi, membawa produktivitas dan kontrol yang lebih baik terhadap proses tersebut. Tapi hanya mengotomatisasi aktivitas yang 
menggunakan teknologi. Memanfaatkan sistem informasi dengan lebih baik berbuat lebih banyak. Menggunakan teknologi untuk mengelola dan memperbaiki proses, baik di dalam perusahaan maupun secara eksternal dengan pemasok dan pelanggan, adalah tujuan akhir.

c) Penelitian Terkait

Adapun penelitian sudah dilakukan oleh beberapa peneliti lainnya antara lain salah satu penelitian serupa yang berjudul Sistem Informasi Pelaksanaan Praktek Kerja Lapangan Berbasis $W e b$, dijelaskan bahwa sistem tersebut sudah memberikan kemudahan kepada fakultas MIPA dalam mengelola data-data pelaksanaan praktek kerja lapangan yang setiap tahun dilakukan. Hal ini terbukti dengan hasil akhir dilakukan saat tahap pengujian. Sistem informasi ini dibangun dengan Web, HTML (Hyper Text Markup Language), PHP, MySQL dan Macromedia Dream weaver [8].

Penelitian dengan judul Rancang Bangun Sistem Informasi Praktek Kerja Lapangan Berbasis Web dengan Metode Waterfall, menjelaskan bahwa pencatatan dan penyimpanan data kurang terstruktur dan kurang rapi, memerlukan waktu yang lama dalam hal pencarian data mahasiswa yang akan melakukan kegiatan PKL dan mahasiswa yang sudah melakukan kegiatan PKL pada tahun sebelumnya, adanya redudansi data sehingga data tidak konsisten, pemborosan space sehinggga memerlukan tempat yang besar untuk menyimpan data kegiatan PKL [9] .

Penelitian yang berjudul Rancang Bangun Sisten Informasi Kuliah Kerja Nyata (KKN) Pada Universitas Muria Kudus. Tujuan penelitian ini yaitu untuk membantu kelancaran kegiatan KKN guna menghasilkan sistem informasi yang berguna dalam menangani proses pendaftaran KKN, pembagian kelompok, penilaian hasil KKN dan sebagai sarana mempublikasikan informasi yang berhubungan dengan kegiatan KKN melalui sistem informasi. Sistem ini dibuat dengan perancagan sistem menggunakan pemodelan Unified Modeling Language (UML) dan menggunakan bahasa pemograman PHP serta database MySQL [3].

\section{METODOLOGI PENELITIAN}

Metode penelitian yang digunakan yaitu Research and Development (RND). RND merupakan salah satu metode penelitian yang digunakan untuk menghasilkan produk tertentu dan menguji keefektifan produk tersebut. Produk tersebut tidak selalu berbentuk benda atau perangkat keras (hardware), seperti buku, alat tulis, dan alat pembelajaran lainnya. Akan tetapi, dapat pula dalam bentuk perangkat lunak (software) [10]. Tahapan penelitian $R N D$ diuraikan sebagai berikut:

a) Penelitian dan Pengumpulan Data

Pada tahapan ini dilakukan pengumpulan data akademik mahasiswa yang berhubungan dengan layanan Kuliah Kerja Dakwah, guna untuk mempermudah peneliti dalam menganalisis data. Dalam hal ini dihasilkan sebuah data layanan akademik mahasiswa. Adapun teknik-teknik pengumpulan data yang peneliti gunakan adalah sebagai berikut:

1) Wawancara

Dalam teknik ini, dilakukan wawancara secara langsung atau tatap muka dengan bagian yang terkait dalam hal ini adalah bagian LP2M untuk mendapatkan data yang dibutuhkan dalam pengembangan sistem.

2) Observasi

Teknik ini dilakukan untuk mendapatkan informasi mengenai $\mathrm{KKD}$, serta menganalisis kebutuhan yang diperlukan dalam membuat sistem.

3) Studi Literatur

Teknik ini, mempelajari literatur yang ditulis oleh para ahli yang berhubungan dengan masalah yang diteliti seperti web Kuliah Kerja Lapangan, permasalahan teori yang ditemukan baik dari buku, internet, perpustakaan dan literatur lainnyayang menjadi acuan dalam analisis dan pengolahan data.

b) Perencanaan

Berdasarkan studi pendahuluan, dibuat perencanaan atau rancangan sistem mencakup :

a. Tujuan penggunaan sistem ini yakni, untuk mengoptimalkan layanan dan informasi tentang KKD untuk mahasiswa.

b. Sistem ini nantinya akan digunakan oleh Mahasiswa dan Admin LP2M

c) Pengembangan Produk Awal

Pengembangan sistem awal merupakan draft kasar atau rancangan dari sistem yang akan dibuat. Akan tetapi draft produk tersebut harus disusun lengkap agar menghasilkan suatu draft yang efektif. 
d) Uji Coba Awal

Pada tahap ini dilakukan uji coba awal draft yang telah dibuat oleh peneliti dan bekerja sama dengan para ahli atau praktisi yang sesuai dengan bidangnya, kemudian para ahli menguji dengan mengevaluasi sebuah draft tersebut. Dalam tahap ini uji coba pemakaian atau evaluasi oleh para ahli bersifat perkiraan berdasarkan analisis dan pertimbangan logika dari peneliti dan para ahli.

e) Revisi Produk Setelah dilakukan uji coba awal kemudian masih terdapat kekurangan dalam pengujiannya, maka dilakukan generalisasi kasus demi kasus yang ada dalam sistem tersebut.

f) Uji Coba Akhir

Setelah uji coba evaluasi dilakukan, maka dilakukan uji coba lapangan. Selama pelaksanaan uji coba di lapangan, peneliti mengadakan pengamatan secara intensif dan mencatat hal-hal penting yang dilakukan oleh responden yang akan dijadikan bahan untuk penyempurnaan sistem awal tersebut.

g) Revisi Produk Operasional

Selama pelaksanaan uji coba di lapangan, peneliti mengadakan pengamatan secara intensif dan mencatat hal-hal penting yang dilakukan oleh responden yang akan dijadikan bahan untuk penyempurnaan sistem awal.

h) Uji Coba dan Penyempurnaan Produk yang Telah Disempurnakan

Meskipun telah memperoleh sistem yang lebih sempurna, tetapi uji coba dan penyempurnaan sistem masih perlu dilakukan sekali lagi. Hal ini dilakukan agar sistem KKD yang dibuat memenuhi standar tertentu.

i) Pengujian Produk Akhir

Untuk menguji apakah suatu sistem pendidikan layak dan memiliki keunggulan dalam tataran praktek. Sistem diasumsikan sudah sempurna. Pengujian produk akhir, dapat dilakukan dengan uji coba tahap ke 2, akan tetapi dengan jumlah sampel yang berbeda.

j) Implementasi

Setelah dihasilkan sebuah sistem yang sudah teruji keampuhannya, langkah selanjutnya adalah mengimplementasikan sebuah sistem yang telah dibuat oleh peneliti.

\section{HASIL DAN PEMBAHASAN}

a) Hasil Penelitian

Tahap implementasi sistem adalah tahap lanjutan setelah metodologi penelitian yang telah di bahas di bab tiga. Tahap ini merupakan tahap mengaplikasikan sistem yang telah di kembangkan berdasarkan hasil penelitian yang telah di lakukan sebelumnya agar sistem siap untuk di oprasikan sesuai dengan yang di inginkan. Tahap implementasi ini bertujuan untuk menyiapkan segala hal yang berkaitan dengan penerapan sistem sesuai dengan rancanga yang di tentukan. Berikut merupakan tampilan SIKKD mulai dari menu login sampai proses penilaian:

1) Flowchart Sistem Berjalan

Flowchart sistem berjalan pada gambar 1 di bawah ini, menggambarkan alur registrasi pendaftara KKD di lingkungan Universitas Muhammadiyah Gorontalo. Dari awal pendaftaran, pembekalan/coaching, turun lapangan sampai proses penilaian. 


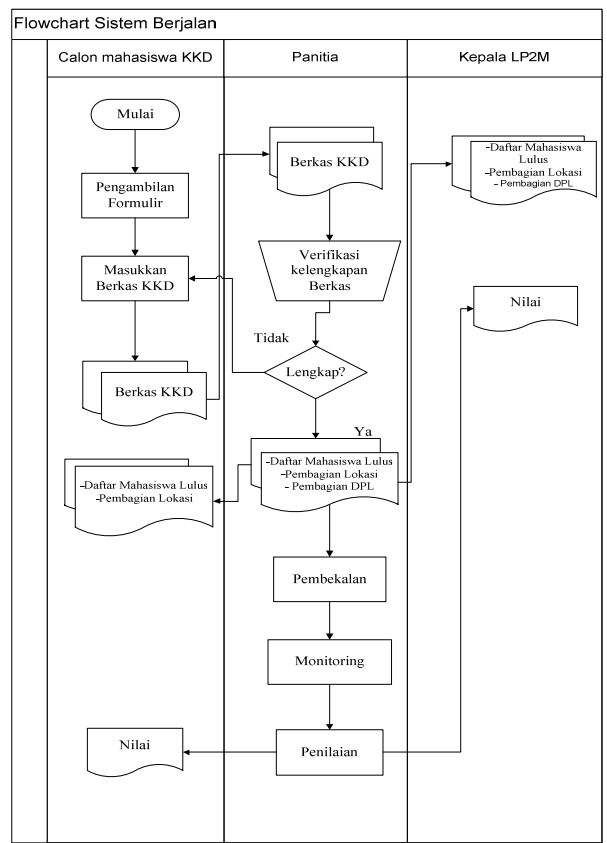

Gambar 1. Flowchart Sistem Berjalan

2) Flowchart Sistem Usulan

Flowchart sistem usulan pada gambar 2 menggambarkan alur dari sistem yang diusulkan berbasil online yakni SIKKD. Seluruh sistem akan dijalankan secara komputerisasi sehingga proses registrasi, penggunggahan berkas, penilaian dan cetak kartu peserta dilakukan dalam system.

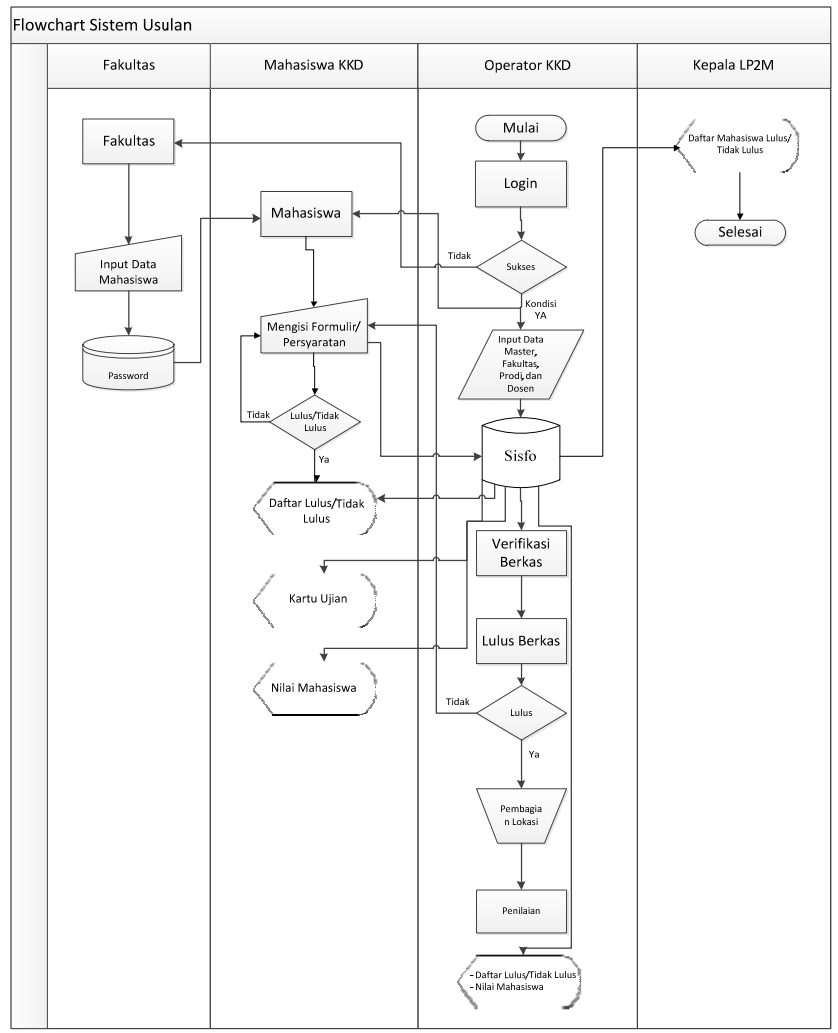

Gambar 2. Sistem Usulan 


\section{3) Entity Relationship Diagram}

Entity Relationship Diagram (ERD) menggambarkan relasi antar database dan sistem berjalan kaitannya dengan atribut yang lain. Dalam sistem ini dapat dilihat hubungan antara seluruh atribut dalam database SIKKD.

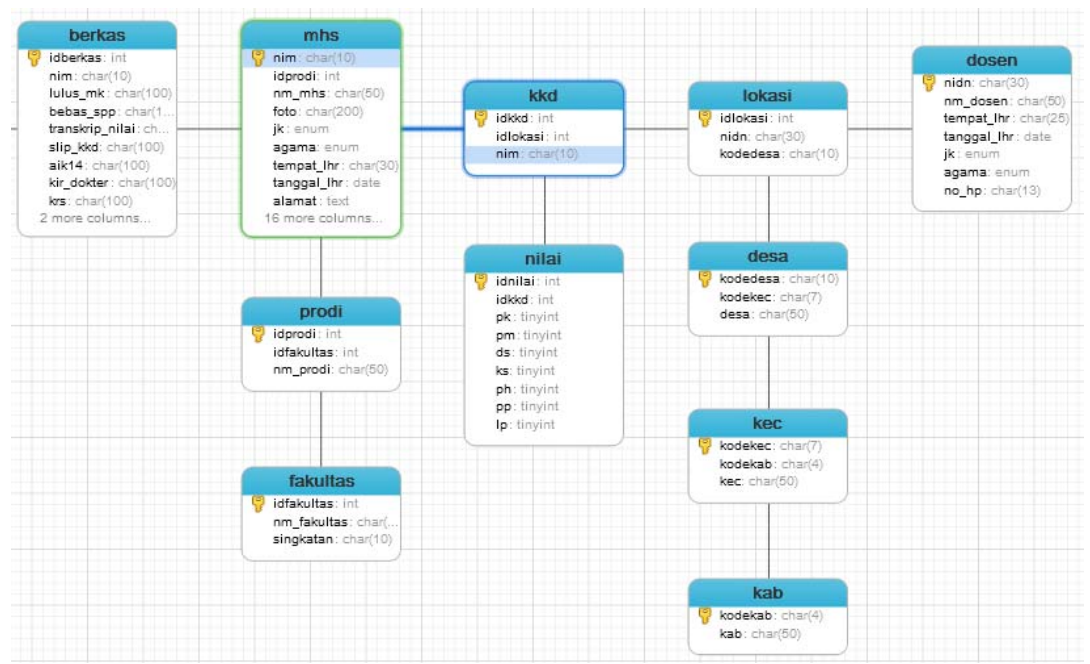

Gambar 3. Entity Relationship Diagram

b) Pembahasan

SIKKD dibuat untuk memudahkan proses registrasi KKD di Lingkungan UMGO, karena kemudahan dalam pengaksesan database, proses registrasi yang cepat, mengurangi estimasi waktu pengurusan, maka SIKKD dibuat untuk menjawab kebutuhan sistem tersebut. SIKKD dibuat lebih "user friendly" baik dari segi tampilan maupun penggunaannya. Jadi operator dari sistem akan dengan mudah mempelajari dan menguasai alur sistem. Fakultas, peserta KKD juga lebih mudah menggunakan sistem ini serta DPL dapat dengan mudah memasukkan nilai ketika proses KKD sudah berakhir. Berikut alur sistemnya:

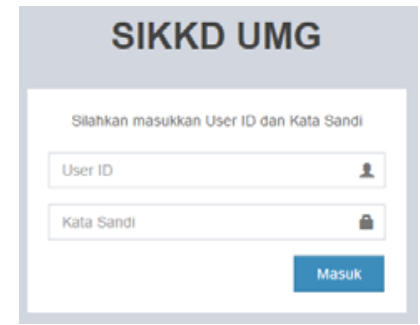

Gambar 4. Form Login SIKKD

Pada gambar 4 di atas menampilkan menu login yang menjadi akses masuk ke dalam sistem sesuai tingkatan pengguna baik mahasiswa sebagai peserta KKD, admin (operator LPPM dan DPL. 


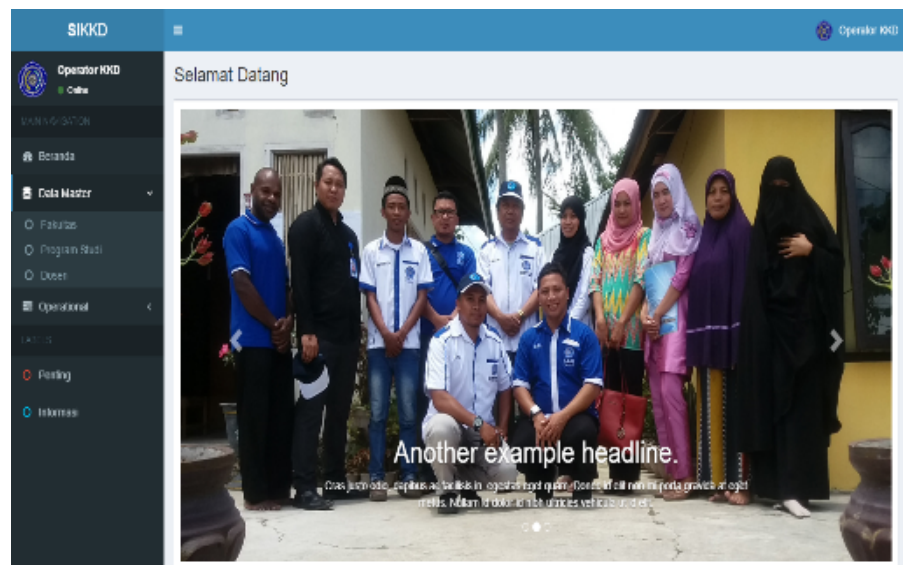

Gambar 5. Form Administrator SIKKD

Pada gambar 5 di ataas menampilakan menu administrator, administrator akan di sambut oleh form menu utama administrator dengan hak akses penuh terhadap sistem, setiap hak akses disediakan dalam bentuk form-form yang kemudian dijadikan menu dan sub-sub menu. Di dalam menu user, terdapat sub menu beranda, data fakultas, data program studi, data dosen, verifikasi berkas, pembagian DPL, pembagian lokasi dan penilaian. Adapun proses jalannnya SIKKD ini dijabarkan dalam gambar 6-11 di bawah ini:

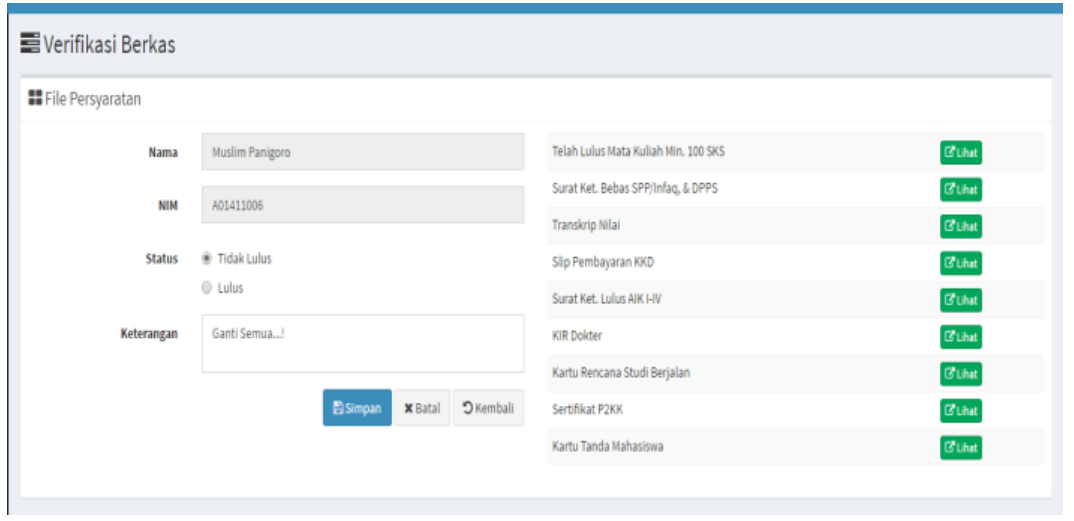

Gambar 6. Form Verifikasi Berkas

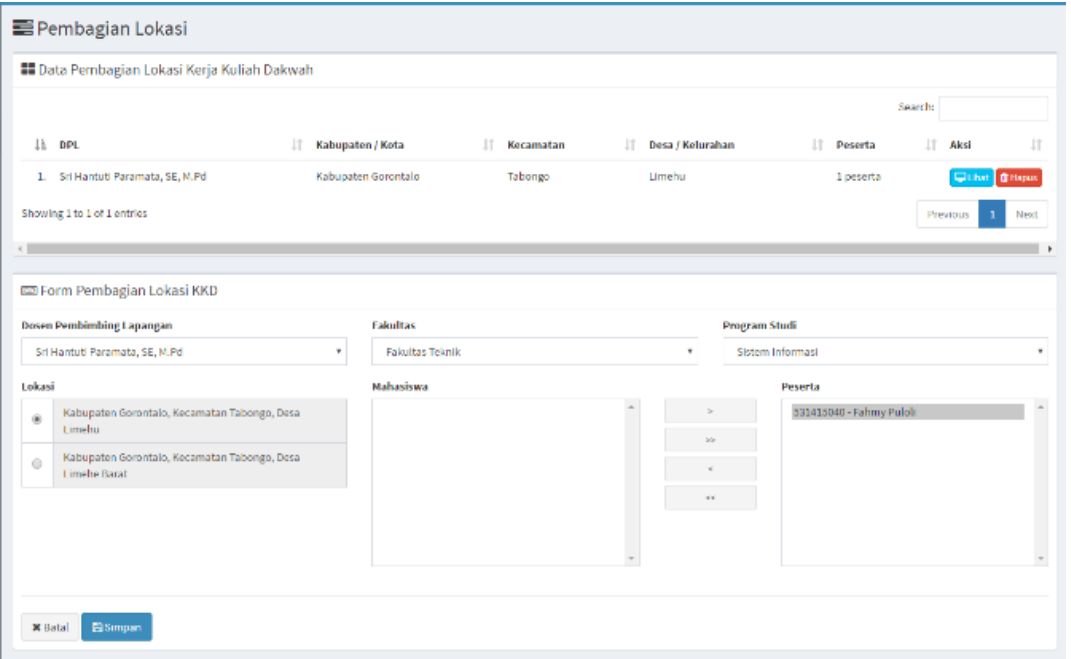

Gambar 7. Form Pembagian Lokasi 
Jurnal SIMETRIS, Vol 8 No 2 November 2017

ISSN: 2252-4983

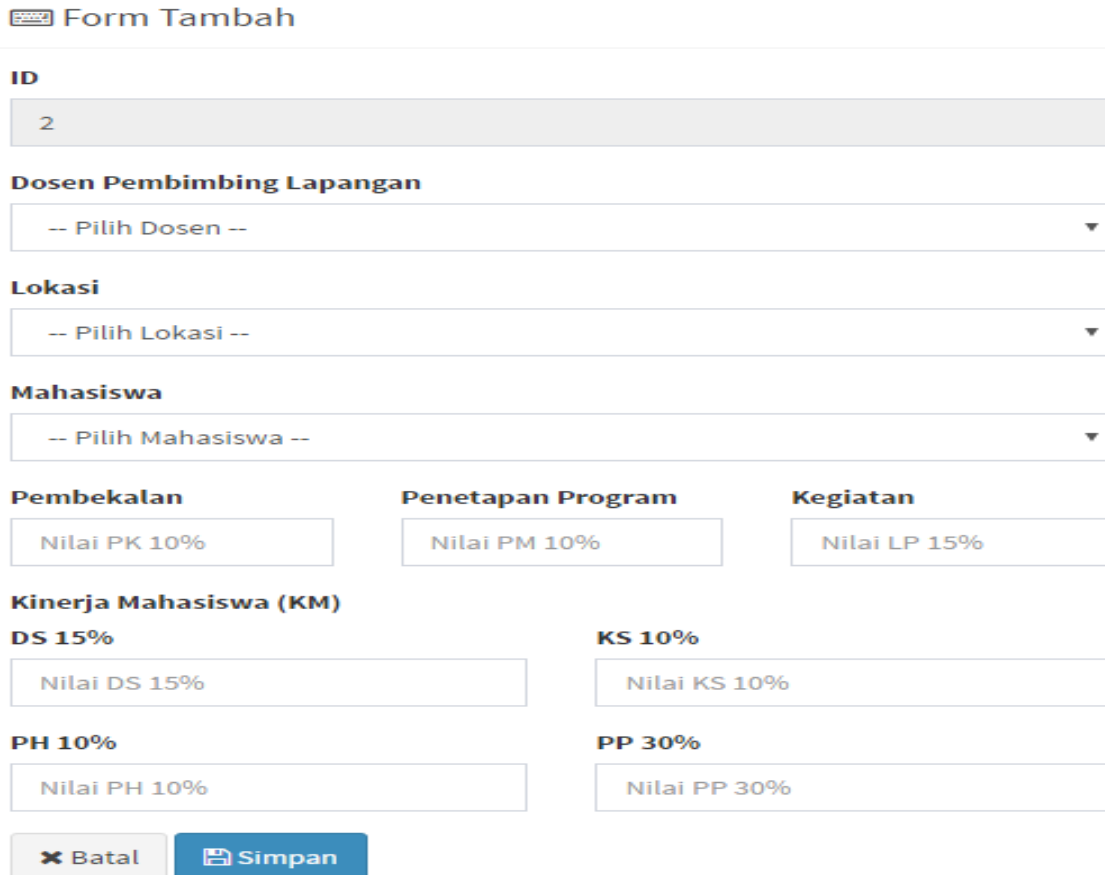

Gambar 8. Form Penilaian

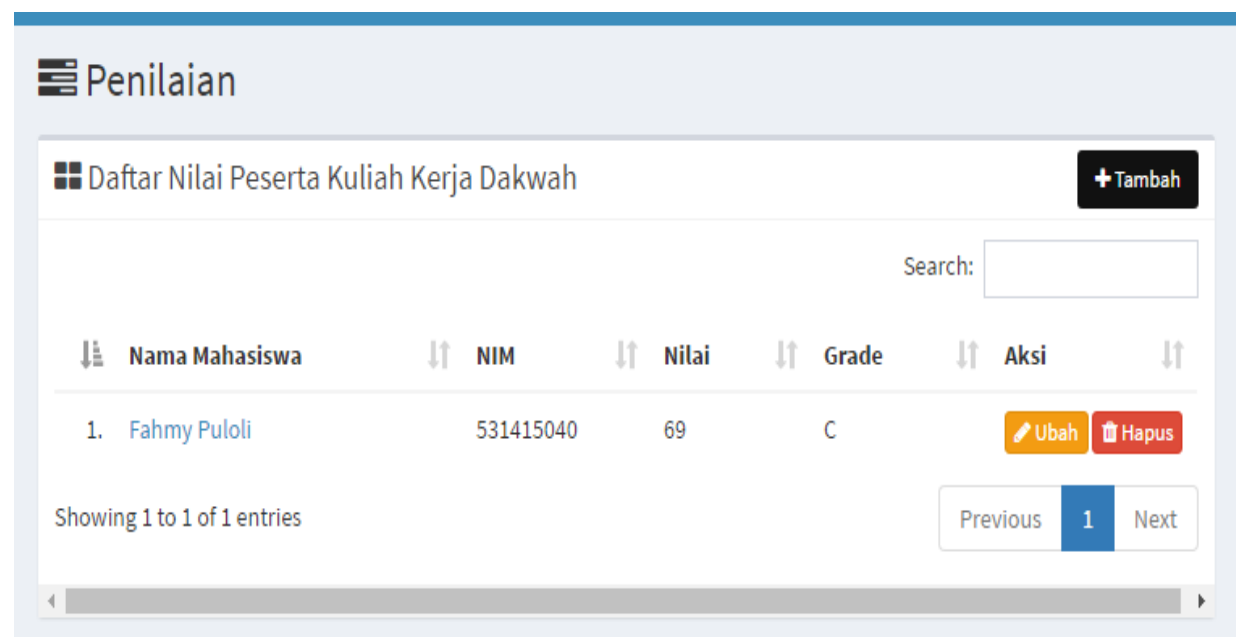

Gambar 9. Form Penilaian 


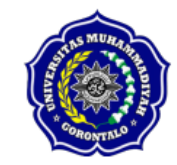

LEMBAGA PENELITIAN DAN PENGABDIAN MASYARAKAT

KULIAH KERJA DAKWAH

UNIVERSITAS MUHAMMADIYAH GORONTALO

Jl. Prof. Dr. H. Mansoer Pateda, Desa Pentadio Timur, Kec. Telaga Biru

Telp.0435-881135, Fax.0435-881136, Website: www.umgo.ac.id, Email: info@umgo.ac.id

DAFTAR NILAI PESERTA KULIAH KERJA DAKWAH

\begin{tabular}{lcccccc}
$\begin{array}{l}\text { Mata Kuliah } \\
\text { SKS }\end{array}$ & $: 4$ & & & & Tahun $: 2017$ \\
& & & & & \\
\hline NO & NIM & NAMA & NILAI & GRADE & BOBOT \\
\hline 1. & A01411006 & Muslim Panigoro & & 100 & A & 4 \\
\hline
\end{tabular}

Gorontalo, 6 April 2017

Kepala LP2M,

Dr. Yuzda Salimi, M.Si

Gambar 10. Form Cetak Nilai

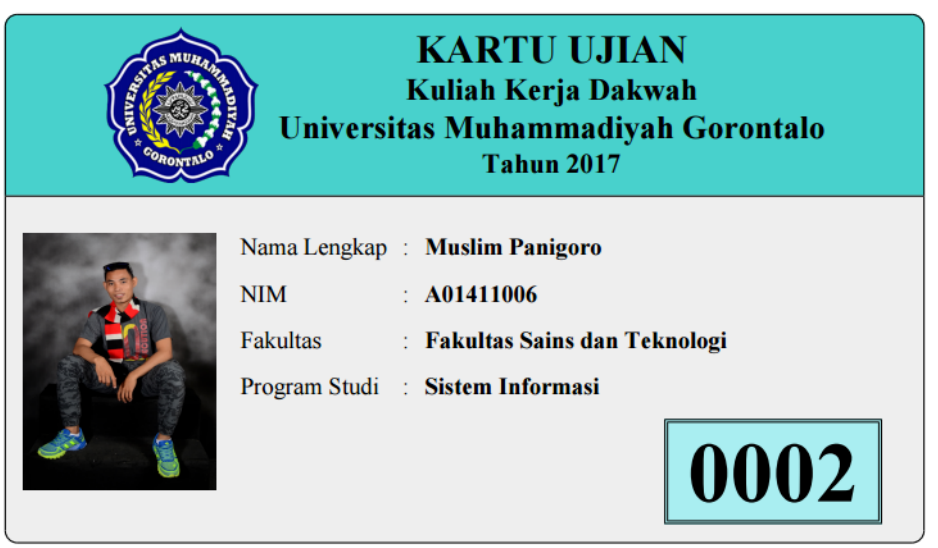

Gambar 11. Kartu Ujian

\section{KESIMPULAN}

Adapun hasil penelitian ini dapat disimpulkan bahwa pengembangan Sistem Informasi Sistem Informasi Kuliah Kerja Dakwah Universitas Muhammadiyah Gorontalo mulai dari tahap perancangan hingga pengujian. Maka dapat disimpulkan :

a) SIKKD dapat memudahkan proses registrasi sampai penilaian dalam KKD.

b) Pengembangan Sistem Informasi Kuliah Kerja Dakwah Universitas Muhammadiyah Gorontalo yang telah di buat dan terdiri atas :

1) Form Verifikasi Berkas.

2) Form Penilaian Berkas

3) Form Nilai Mahasiswa

c) Database dari sistem menggunakan MySQL 


\section{DAFTAR PUSTAKA}

[1] S. Informasi, F. Teknik, and U. Widyatama, "Perancangan Sistem Informasi Kependudukan Sebagai Pengembangan E-Goverment," vol. 2, no. 1, pp. 1-5, 2017.

[2] N. Latifah, P. Studi, S. Informasi, and U. M. Kudus, "Perancangan Sistem Informasi Pengelolaan Administrasi Dokumen Pendaftaran Skripsi,” vol. 7, no. 2, pp. 60-64, 2016.

[3] G. Fandatiar, "Rancang Bangun Sistem Informasi Kuliah Kerja Nyata ( KKN) Pada Universitas Muria Kudus," vol. 6, no. 1, pp. 129-136, 2015.

[4] F. Anasari, A. Suyatno, I. F. Astuti, P. Studi, I. Komputer, and U. Mulawarman, "Kuliah Kerja Nyata Berbasis Digital (Studi kasus: Lembaga Pengabdian kepada Masyarakat Universitas Mulawarman )," vol. 10, no. 1, pp. 11-19, 2015.

[5] S. Ratnaningtyas, P. S. Sasongko, and H. A. Wibawa, "Sistem Informasi Geografis Untuk Pemetaan Posdaya Di Kabupaten Semarang Berbasis Scalable Vector Graphics (SV)," vol. 1, no. 1, 2012.

[6] U. P. Ganesha and U. P. Ganesha, "Pengembangan Sistem Informasi Geografis Kuliah Kerja Nyata (KKN) UNDIKSHA Berbasis Teknologi Mobile dan Location Based Service."

[7] D. T. Bourgeois, Information System for Business and Beyond. Open Text Book Challenge.

[8] A. S. Sinambela, "Sistem Informasi Pelaksanaan Praktek Kerja Lapangan Berbasis Web Pada Jurusan D3 Ilmu Komputer Departemen Matematika Universitas Sumatra Utara," 2008.

[9] S. T. and D. Supriyadi, "Rancang Bangun Sistem Informasi Praktek Kerja Lapangan Berbasis Web Dengan Metode Waterfall," 2015.

[10] Jogiyanto, Analisis dan Desain Sistem Informasi. Yogyakarta: Andi Yogyakarta, 2005. 